\title{
Two Hearts Believing in Just One Mind? The Humanistic Management Network and the Global Ethic Project
}

\author{
Jonathan Keir ${ }^{1}$
}

Received: 3 September 2015 / Accepted: 23 October 2015 / Published online: 3 August 2016

(C) Springer International Publishing 2016

\begin{abstract}
It is drearily fashionable to criticise the business community for its chronic refusal to take values - beyond the bottom line - seriously. A more honest investigation of the phenomenon of moral bankruptcy in global business and finance, however, reveals that a prior crisis among humanists - widespread denial of the very existence and even desirablility of universal values - predates the financial crises and big business scandals of recent decades, and deserves a healthy portion of the blame for them. Opposition to this quest for common values takes many forms, principled as well as practical. Values, it is commonly argued, belong in the realm of individual freedom; organisations, including corporations, have no business trying to impose moral preferences on their employees. The only solution fit for the 21 st Century, with its highly differentiated and increasingly global labour markets, is, on the standard neoliberal account, to leave individuals alone to pursue their own conceptions of the good life on the condition that they display a minimum of respect for the rule of law within the organisations in which they operate. Such ethical minimalism, however, leaves a society more or less defenceless against the excesses of its most powerful actors, which today most certainly include multinational corporations. Without demanding higher, global standards of ethical responsibility beyond mimimum legal compliance, a 'race to the bottom' among business actors desperate for survival is, and has been, the inevitable result of this total abandonment of higher humanistic principles. The reintroduction of Basic Trust, necessary for all ethical behaviour, into the system in which global managers operate - an impossible task without turning to an updated global patrimony of humanistic learning - is the common goal of the Humanistic Management Network and the Global Ethic Project. This brief paper critically explores the paths to reform proposed by the two movements, and shows how each can play an important supporting role in helping the other to achieve its main goals.
\end{abstract}

Keywords Humanistic Management Network · Global Ethic Project

Jonathan Keir

keir@weltethos-institut.org

1 Weltethos-Institut, Universität Tübingen, Hintere Grabenstraße 26, 72070 Tübingen, Germany 


\section{Introduction}

It is drearily fashionable to criticise the business community for its chronic refusal to take values - beyond the bottom line - seriously. A more honest investigation of the phenomenon of moral bankruptcy in global business and finance, however, reveals that a prior crisis among humanists - widespread denial of the very existence and even desirablility of universal values predates the financial crises and big business scandals of recent decades and deserves a healthy portion of the blame for them. The idea that the humanities - philosophy, literature, art, music and their cousins - contain moral knowledge, or concrete practical wisdom of any kind, has been cast to the winds (Scruton 2013) by recent generations of Western intellectuals and their global followers in favour of a postmodern relativism which tacitly, and by default, has encouraged 'scientists', including social scientists and economists, to pursue research agendas which, far from being 'value-neutral' as is often claimed, in fact pursue the sole value of boosting economic productivity.

Founded in 2005, the Humanistic Management Network represents a reaction against the obvious excesses and deficiencies of such monomaniacal thinking. At the heart of the HMN's 21 st-century mission is the recovery of the best of an older, largely discredited model, in which a general education in the 'liberal arts' or humanities was considered a prerequisite for responsible leadership. While knowledge of Greek and Latin (or, in a Chinese context, classical Chinese) and other markers of high culture may often have served as a filter of social class and as a barrier to entry designed to secure the rights of inherited (male) privilege, the assumption that such 'humanistic' learning at its best contained practical wisdom for future managers, not distillable in any other form, was widely shared and, before about 1968, rarely challenged.

The Global Ethic Project can also be interpreted as an attempt to recover the best of humanity's cultural past and to transmit 'practical wisdom' into our globalised future. The brainchild of Catholic theologian Hans Küng, the Global Ethic Project has, since its inception in 1990, sought first and foremost to promote interreligious dialogue among the world's major faiths but, following its own definition of 'dialogue' as meaningful two-way exchange, has expanded its mandate in recent years to include the non-religious world and to tackle the big 'secular' questions of global political and economic reform of the early 21 st Century.

Opposition to this quest for common values takes many forms, principled as well as practical. Since no two individuals can ever fully agree on values or the best language to express them, the attempt to create common values is often prematurely dismissed as either futile or sinister. The only solution fit for the 21 st Century, with its highly differentiated and increasingly global labour markets, is, on the standard neoliberal account, to leave individuals alone to pursue their own conceptions of the good life on the condition that they display a minimum of respect for the rule of law within the organisations in which they operate.

Such ethical minimalism, however, leaves a society more or less defenceless against the excesses of its most powerful actors, which today most certainly include multinational corporations. Without demanding higher, global standards of ethical responsibility beyond mimimum legal compliance, a 'race to the bottom' among business actors desperate for survival and an abandonment of higher humanistic principles are, and have been, the inevitable result. The reintroduction of the conditions necessary for ethical behaviour into the system in which global managers operate an impossible task without turning to an updated global stock of humanistic learning - is the common goal of the Humanistic Management Network and the Global Ethic Project. This brief paper critically explores the paths to reform proposed by the two movements, and shows how each can play an important supporting role in helping the other to achieve its goals. 


\section{The Humanistic Management Network: Towards a 'Humanistic Consensus' on Global Business}

Little ethical nuance or sophistication would seem to be required to denounce the most egregious corporate wickedness; lying and theft are deplored by most ordinary people even if legal loopholes exist in particular times and places which allow individual companies to get away with dishonest practices without criminal sanction. In this gloomy context, the legalistic argument that better regulation and stauncher enforcement are the best ways to prevent businesses from lying and thieving in the future can be juxtaposed with the legalistic counter-argument that the law will always lag behind the real world and, in any case, be less than perfectly enforced:

While national and international laws seek to mitigate and curb harmful outgrowths of corporate power and its misuse, laws, especially in a globalising world of complex relations, encounter functional limits. Since the hand of justice oftentimes reaches too short and grasps too crudely, self-commitment and self-restraint as well as moral integrity and moral leadership must support legal force (Dierksmeier and Hoegl 2014, p. 74).

If one stands by the first legalistic argument, then one has no real need for either ethics or humanism in business; if one accepts the legalistic counter-argument, then companies must take the idea of morality seriously for an important practical reason, namely so that the legal system is not overburdened and can be relied upon to deal with the most extreme and obvious cases of illegality and corruption which, in any society composed of human beings, will sooner or later be uncovered by those charged with looking.

There remains, however, a third, 'humanistic' argument, unsurprisingly promoted by the HMN, according to which business actors realise their highest selves and the meaning of their existences through virtuous behaviour. This is a much, much harder sell to business leaders typically consumed with the mere day-to-day survival of their enterprises, and must therefore be marketed very, very carefully, in the first instance by picking off all available 'low-hanging fruit' - to rehearse the management field's regrettable and decidedly unhumanistic preference for cliché - and promoting, wherever possible with real-world case-study examples (e.g. von Kimakowitz et al. 2011; Spitzeck et al. 2012), the idea that ethical behaviour of one kind or another actually increases short-term profits. There is, of course, nothing intrinsically 'ethical' or 'humanistic' about this, but such a 'methadone approach' may be a useful first step on the path to getting truly clean from profit addiction. The HMN is much more than a marketing platform for superficial ethicality - it is interested in building intellectual capital on all levels in the interests of humanising business policy and practice - but part of this mandate involves a willingness to meet the business community on its own turf.

The HMN's real challenge begins when the feel-good effects of the methadone approach begin to wear off, and when businesses must face the very real prospect of having to sacrifice short-term profits in the name of ethics or humanism. The next phase of rehab, which still relies on the promise of methadone, entails training managers, again with the help of examples and case studies, to sacrifice short-term profits for longer-term ones. The precise contours of this humanistic reorientation of global business are a subject of healthy debate within the HMN community, just as methadone treatment is a topic of fierce discussion in drug rehab circles; make the treatment too hard or too foreign and you will discourage all reform, but make it too easy and you will only prolong the dependency. The HMN exists to challenge the a priori 
assumption that ethical business models cannot succeed in the real world - a prejudice worth challenging for its own sake - by uncovering as many examples as possible of firms who manage durably to marry 'principles and profits'. The business community, too long tied to quantitative, homo economicus-inspired short-term models, has systematically blinded itself to the potential long-term economic benefits of such 'strategic innovation', needlessly costing itself money and dumping unwanted externalities onto third parties (Dierksmeier 2011).

In the meantime, the HMN remains as committed to prevention as to cure, and is investing its long-term hopes in educational reform. In their conclusion to Humanistic Ethics in the Age of Globality (2011), the editors approvingly cite Keynes's famous dictum that 'in the field of economic and political philosophy there are not many who are influenced by new theories after they are 25 or 30 years of age'; humanistic business leaders are not born, but must be made by reforming tertiary business school curricula as well as business education at primary and secondary levels. In drafting the philosophical outlines of this new curriculum, the editors asked their contributors

to forego the pleasures of the academic's favourite hobby - looking for differences - and instead to seek out and emphasise features common to their subjects. We [want] to know what extent the economic philosophers of different periods and places agree, to find out whether a humanistic consensus for business ethics can be derived from their arguments (Dierksmeier et al. 2011, p. 271).

The editors' ensuing 'Western heritage tour' through Socrates, Plato, Aristotle, Aquinas, Kant and even Marx, all of whom counsel directly against 'the unbounded pursuit of wealth', threatens to run aground only when it reaches postmodernity: 'Otherness is not for us to define; the other is respected when we honour his or her self-determination. A procedural approach to humanistic ethics therefore seems to be the way forward.' This token reference to the prevailing relativism of the age does not, however, prevent the editors from refusing 'as too simple all wholesale dismissals of universalistic positions as unjustifiable narratives of Eurocentric origin'; instead of 'identifying each part of the world with a unique, fixed, and uniform set of values', a globalised, humanistic business education fit to meet the challenges of the 21 st Century must cultivate 'a readiness to reconsider our own cherished beliefs in the name of the one humanity on whose behalf we are debating'. Following Kresse, the editors conclude, for example, that the 'overarching consensus of the various humanistic traditions of Africa' namely 'the important insight that a human being is and becomes human (as well as humane) through others' - must be integrated into a wider global 'consensus' which transcends Western humanism and incorporates the best of other civilisational traditions, including Chinese, Indian, Arab and so on (Dierksmeier et al. 2011, pp. 286-291).

Attractive as it may sound to praxis-oriented business audiences, this very language of 'consensus', if misunderstood, may nevertheless turn out to be part of the problem rather than the part of the solution. If the values of other cultures are only ever 'compatible' of 'incompatible' with our own existing values, then by definition they can have nothing of their own really to teach us. A humanistic middle way is therefore sought by the HMN between a fundamentalist insistence on blindly promoting one's own existing value system at the expense of all others and a relativism which refuses the right to pass judgements at all on questions of morality. The 'consensus' on which the HMN is counting is in fact the outcome of a genuine dialogue between individuals and groups who take the possibility of learning something new from each other seriously. In many respects, this very readiness already is the consensus, or at 
least a necessary part of it; as Amann and Stachowicz-Stanusch argue in their 'Emerging Insights on How to Build More Humanistic Organisations with Integrity', 'great leaders thus realise where their gaps exist, be it on the knowing level - knowing what is right in their situation; or on the doing level - ensuring effective implementation; or on the being level having clarified for themselves what kind of leaders they want to be' (Amann and StachowitzStanusch 2013, p. 603). None of this is possible without an ongoing willingness to learn from others and to engage in genuine self-critique.

In other words, even the most bottom-line-driven, profit-addicted business leader must, if she is not simply to be dismissed as a fundamentalist or psychopath, be at least capable of evaluating the emotional pleas and rational arguments for ethics and humanism in business from the likes of the HMN, just as the HMN and humanists in other walks of life must be willing to weigh the arguments for profit-centred rationales for certain business decisions from real-world business leaders; not all profit can be the problem. Out of this free exchange, in which both sides accept the possibility of learning something new from the other, a new 'humanistic consensus' for business, freed from the 'prisoner's dilemma' of pursuing profit for profit's sake, has a chance of emerging; without such trust in dialogue, however, the 'two cultures problem' - the ivory tower of the business ethicist versus the coal-face of the business executive - looks set to persist, along with the disastrous consequences - environmental, social and political - of the prisoner's dilemma itself, in which individual firms pursuing their own prosperity, and more often than not their own mere survival, produce unacceptable externalities. The HMN therefore needs to cultivate trust most urgently among its business readership; making plausible 'business cases' may be important and necessary as first steps in the right direction, but eventually, the methadone must be wholly dispensed with: trust must sooner or later be sought for its own sake, and the HMN has recognised this with a series of theoretical studies as well as case study volumes (e.g. Amann and Stachowitz-Stanusch 2013; Beabout 2013). It is precisely here that the Global Ethic Project has the most to offer the HMN as it seeks further to develop its 'intellectual core' over the coming years via academic journal initiatives such as the present volume.

\section{The Global Ethic Project: Towards a Consensus on Basic Trust}

Interreligious dialogue may seem an odd place in the world to start looking for trust. Global Ethic Project founder Hans Küng, however, places the idea of Basic Trust - Grundvertrauen in the original German - at the centre of his ecumenical efforts:

We can observe that many non-Christians say Yes to life too, such as it is, and to the idea of a meaning of life. This affirmation is invariably bound up with conceptions of guilt and grace, but does not by definition have, or need to have, anything specifically Christian or Catholic about it. The idea of Basic Trust is therefore, for me, the foundation of a Basic Ethos that can unite us all. For without this 'acceptance' of reality, without this positive, trusting Yes to reality despite all temptations to reject it, no one can behave ethically. Basic morality presupposes a Basic Trust in reality (Küng 2002, p. 21).

The implications of this worldview extend directly out of the ivory tower of academic theology and into the real world of the urban rat race:

Later in life it became clearer and clearer to me that Trust was of incalculable importance for the health of society as a whole, even for international politics and the global 
economy. [...] I in no way exaggerate when I describe Trust as the basis of all human social life. (Küng 2010, pp. 37-38)

Küng delves into developmental psychology to locate the roots of this Basic Trust in healthy human relationships during early childhood, arguing that the ability to trust reality, and therefore to take the idea of moral responsibility seriously, depends heavily on one's relationship with one's parents and primary caregivers: 'How could a young person in particular possibly understand what it means to be accepted by God' - or in more secular language, to heed the call of morality - 'when she has never been properly accepted by a single human being?' (Küng 2013, p. 25). The chief consequence of this default setting of Basic Trust, for our purposes here at least, is the readiness, not automatically to accept new ideas, but always to be ready to face them and to evaluate them on their own merits, in the hope of learning something new and trusting in the outcome of the unpredictable chemical reaction of contact. In the context of interreligious dialogue, this means accepting that other religious, spiritual and philosophical traditions may always have something new, interesting, important and true to say; in the context of business ethics, it means a willingness on the part of business leaders as well as management academics to consider, without undue fear, the idea that business may be about more than short-term profit maximisation. A conception of profit as an end in itself reflects, or at least seems to reflect, a Basic Mistrust in reality: in a trustless universe, profit is the only conceivable defence against the vicissitudes of the future. Just as human beings must accept their own mortality and learn, somehow, to trust in the ultimate benevolence of the reality which condemns them to the fate of death (morality itself, Küng argues, depends on this very acceptance), so too must businesses accept that they are ultimately mortal, and serve a higher purpose than their own continued existence. This does not mean that businesses should not strive to survive and prosper, just as healthy human beings should, only that the very meaning of their activity entails a willingness, when necessary, to sacrifice personal gain, and in extreme situations even to sacrifice their own continued existence, at the altar of Basic Trust. When businesses are born into a world of mortal dangers and furious competition for survival, however, business leaders must bring their own Basic Trust as individuals, acquired in childhood and then through a formal 'humanistic' education, to their roles; they are unlikely ever to acquire it 'on the job'.

In this sense, the provisional two-plus-four 'consensus' on values achieved in the 1993 Declaration Toward a Global Ethic and signed by religious leaders from around the world, though it remains an important landmark in the history of intercultural exchange and may survive as Küng's most lasting contribution to ecumenical discourse, is only really a line in the sand, just as the movement's later formulation of a Global Economic Ethic in response to the 2008 financial crisis is an attempt to make explicit the Basic Trust which should already be implicit in all economic and financial transactions; the principles of humanity, reciprocity, respect for life, respect for truth, respect for honesty and respect for gender equality on which these twin Declarations rest all flow directly from an attitude of Basic Trust towards reality, in which values beyond oneself and one's own survival matter. The six core Global Ethic principles may look good in commandment form on an office wall and allow businesses to claim cheap, easy and conspicuous membership of the Ethics Club, and may even serve as a useful heuristic or mnemonic tool for office staff from time to time, but the real work of the Global Ethic Project, as in the case of the HMN, is that of cultivation, which must principally be undertaken in families and classrooms before individuals even reach the workplace; businesses themselves cannot be 
expected to provide their managers and employees with an entire humanistic education once they arrive there. What can be demanded of business, however, as of all religion in the 21 st Century, is that it take the idea of Basic Trust in reality - entailing a willingness always to learn from that reality - seriously. Defining how the business community can best do that is the joint project of the HMN and the Global Ethic movement over the years ahead.

Küng's own approach to this challenge so far has been distinctly practical; his most sustained address to a business readership, Anständig Wirtschaften: Warum Ökonomie Moral Braucht (Better Business: Why the Economy Needs Morality) (2012), is principally a diagnostic endeavour which goes on to prescribe and point to the cure but, like a number of similarly laudable HMN efforts (e.g. Beabout 2013; Scharmer and Kaufer 2014), stops short of actually administering it. As with any medical condition or social problem, however, diagnosis and accurate prescription are the first and most crucial steps towards recovery; Küng's Global Economic Ethic Manifesto, reproduced at the end of Anständig Wirtschaften, arguably takes the first step beyond simple prescription, serving as a bright-coloured medicine container designed to catch the attention of those who are not yet fully aware that they need to be taking what is inside. Like the HMN, the Global Ethic Project in general and the Global Economic Ethic Project in particular are now faced with the more delicate and frustrating but ultimately more rewarding task - humanistic rather than diagnostic or prescriptive - of coaxing the addict into taking it.

\section{Two Hearts Believing in Just One Mind?}

'Beating together, till the end of time.' The immortal words of Phil Collins may slightly overstate the synergy of the HMN and the Global Ethic Project, but the general point remains: the two movements complement and ultimately need each other, one for theoretical underpinning and the other for real-world relevance. Changing the existing 'dog-eat-dog' business culture of the early 21 st Century will require both time and intelligent effort, but the positive social effects of such a transformation would, both parties agree, be enormous given the influence of contemporary business on society. The Global Ethic Institute in Tübingen, founded in 2012, has assumed this lofty mission as its mandate, marrying theory to practice via classroom teaching, research and public engagement. Three joint HMN-Global Ethic Institute conferences have now been held in Tübingen, bringing academics, businesspeople and students together under the banners 'Integrity and Business: The Key to Enduring Business Success', 'Dignity and Business: The Role of Human Rights and Human Responsibilites', and 'Prudent Business: Practical Wisdom for Managers'. Two further conferences - 'Freedom and Responsibility: Leading for Well-Being and 'Global Ethic: Humanistic Management in the Age of Globality' - are planned over the next 2 years. The goal of building a 'humanistic consensus' for business by putting together, in one room, people who are not accustomed to meeting each other remains a noble one even if the outcomes of such meetings have not, so far at least, typically been immediate road-to-Damascus conversions to new humanistic business models on the part of the business leaders in attendance. At the very least, however, they mark the first baby steps towards the widespread reform sought by both movements; the founding of the present journal on the back of the Palgrave Macmillan Humanism in Business Series publications arguably represents a further milestone in the HMN's short but energetic history.

The theme of trust - the very oxygen of the HMN and Global Ethic initiatives - is of course by no means new to management discourse (e.g. Pirson and Malhotra 2011; Pirson 2007; Fukuyama 1996); Greg Latemore provides one recent example, and a helpful overview of the existing 
literature, in his 2013 chapter in the Humanism in Business Series volume Integrity in Organisations: Building the Foundations for Humanistic Management, offering us such conclusions as: 'Trust and repair are important in buiding integrity'; 'Trust is an increasingly important issue in today's organisations and to subjective well-being'; and 'one builds and restores trust by displaying vulnerability, integrity, competence, consistency, loyalty and openness' (Latemore 2013). These claims are all no doubt true - Latemore cites emprical studies which ostensibly prove them - but the deeper goal of the HMN and the Global Ethic Project is a normative one, namely to move beyond the instrumentalisation of trust - why companies need this scarce commodity in order to survive and prosper - towards a 'humanistic' model in which trust is valued for its own sake. The best way of winning trust, and the significant fruits of trust, may indeed be to display trust and trustworthiness oneself, but as long as one's real goal is profit as an end in itself, rather than an actual extension of trust in the name of a higher goal, then such trust will never be real, and therefore never be lasting. Making the narrow business case for greater trust - the methadone approach - may be worth doing for short-term tactical reasons but in the long run it paradoxically threatens to undermine the whole concept of trust in the first place.

The longer-term challenge for both movements, therefore, is this: merely describing what is needed - important though description undoubtedly is - is never going to be enough to make the transformation to humanistic management magically happen. Case studies are always welcome the more the merrier - and philosophical arguments, such as those of Aristotle, Aquinas and others rehearsed by Dierksmeier, Beabout and company, help the cause and should in no way be neglected, but the HMN and the Global Ethic Project seek a broader 'humanistic turn' away from mechanistic and quantitative models, a paradigm shift which includes philosophical reflection as an important pillar of a humanistic education but which also embraces the wisdom of other humanistic traditions - literature, art, music, religion and so on, crucially extending to the philosophical arguments and wider humanistic patrimonies of foreign cultures - as reinforcers of the Basic Trust in reality which first takes root in childhood and which makes all adult morality possible. No number of PowerPoint slides telling new generations of business students that 'Trust is important' or 'Character plays a central role' can actually do the difficult work of building 'trust' and 'character' to begin with; this is precisely why humanists have as much responsibility - in their roles as parents, guardians, schoolteachers and university educators - for the current perceived 'crisis' in global business culture, and its eventual resolution, as business leaders themselves. The HMN and the Global Ethic Project, for all their differences of orientation and mission, stand shoulder to shoulder in their determination to fight this battle for the humanistic reform of global business on as many fronts as necessary.

\section{Concluding Remarks}

Not even Adam Smith, lazily regarded as the primordial apologist for laissez-faire profitism, ever thought that profit alone should drive economic actors; the great moral philosopher's original vision for business incorporated 'legal strictures against fraudulent and exploitative contracts', 'political governance of the economy through sizable taxes and vigilant regulation', 'sound social mores and customs' and above all 'personal morality, based emotionally on sympathy' (Dierksmeier and Hoegl 2014, p. 64). Beyond methadone and manifestos, the HMN and the Global Ethic Project are above all in Smith's business of sympathy cultivation, defending a concrete idea of morality for its own sake and refusing traditional liberal neutrality regarding 'conceptions of the good life': a life rich in Basic Trust, and the meaning in social life beyond 
oneself which one finds through such trust, is qualitatively better than a life poor in it. Dierksmeier's own model of 'qualitative freedom', an avowed extension of Küng's Global Ethic work to economic theory (and the subject of a forthcoming book), makes this connection explicit:

Because qualitative freedom seeks social interdependence, not independence, it is capable of embracing social justice, ecological sustainability and the rights of future generations more aptly than quantitative freedom. As such, the notion of qualitative freedom ought to be central not only to future conceptions of a sustainable economy, but also to any ethics of global governance (Dierksmeier and Hoegl 2014 p. 71).

'Social interdependence, not independence'; this motto almost perfectly encapsulates the humanistic orientation of both the HMN (Pirson et al. 2014) and the Global Ethic Project. Cultivating an actual lived preference for the risks and weaknesses of interdependence, however, over the mirage of strength and independence promised by limitless profits is hard work in any age, perhaps never moreso than in ours. Whatever other challenges we face, without the active cultivation of a Basic Trust extending not just to family and the local tribe but fit for a newly globalised world, the joint task which the HMN and the Global Ethic Project have set themselves - a humanistic transformation of management education and corporate culture - will remain impossible.

\section{References}

Amann, Wolfgang, and Agata Stachowitz-Stanusch, eds. 2013. Integrity in organisations: building the foundations for humanistic management. Palgrave-Macmillan.

Beabout, Gergory R. 2013. The character of the manager: from office executive to wise steward. Palgrave Macmillan.

Dierksmeier, Claus. 2011. The freedom-responsibility nexus in management philosophy and business ethics. Journal of Business Ethics 101: 263-283.

Dierksmeier, Claus, Wolfgang Amann, Ernst von Kimakowitz, Heiko Spitzeck and Michael Pirson eds. 2011. Humanistic ethics in the age of globality. Palgrave Macmillan.

Dierksmeier, Claus and Katharina Hoegl. 2014. A global ethic for globalised business. In Another state of mind: perspectives from wisdo traditions on management and business, eds. Robert Blomme and Bertine van Hoof, 62-76. Palgrave Macmillan.

Fukuyama, Francis. 1996. Trust: the social virtues and the creation of prosperity. Free Press.

Küng, Hans. 2002. Wozu Weltethos? Religion und Ethik in Zeiten der Globalisierung. Freiburg: Herder.

Küng, Hans. 2010. Was ich glaube. Munich: Piper.

Küng, Hans. 2013. Was bleibt: Kerngedanken. Munich: Piper.

Küng, Hans. 2012. Anständig Wirtschaften: Warum Ökonomie Moral Braucht, vol. 2010. Münich: Piper.

Latemore, Greg. 2013. Restoring trust in two Australian organisations: the cases of Herron and Qantas. In eds. Amann and Stachowitz-Stanusch, 119-145.

Pirson, Michael. 2007. Facing the trust gap: measuring and managing stakeholder trust. St. Gallen: University of St. Gallen.

Pirson, Michael, and Deepak Malhotra. 2011. Foundations of organizational trust: what matters to different stakeholders. Organization Science 22(4): 1087-1104.

Pirson, Michael, Ulrich Steinvorth, Carlos Lagarcha-Martinez and Claus Dierksmeier, eds. 2014. From capitalistic to humanistic business. Palgrave Macmillan.

Scharmer, Otto and Katrin Kaufer. 2014. Transforming capitalism and self: from ego-system to eco-system economies. In Pirson et al., 190-205.

Scruton, Roger. 2013. Scientism in the arts and humanities, http://www.thenewatlantis. com/publications/scientism-in-the-arts-and-humanities, (Accessed 26 November 2015).

Spitzeck, Heiko, Michael Pirson and Claus Dierksmeier, eds. 2012. Banking with integrity: the winners of the financial crisis. Palgrave Macmillan.

von Kimakowitz, Ernst, Michael Pirson, Heiko Spitzeck, Claus Dierksmeier, Wolfgang Amann, eds. 2011. Humanistic management in practice. Palgrave Macmillan. 